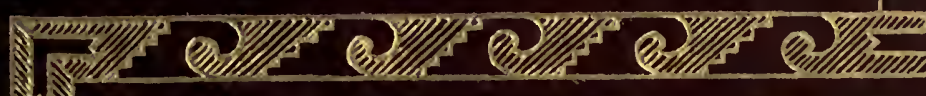

N.

as

W

(1)

(1)

(a)

는

(4)

ᄂ

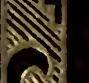
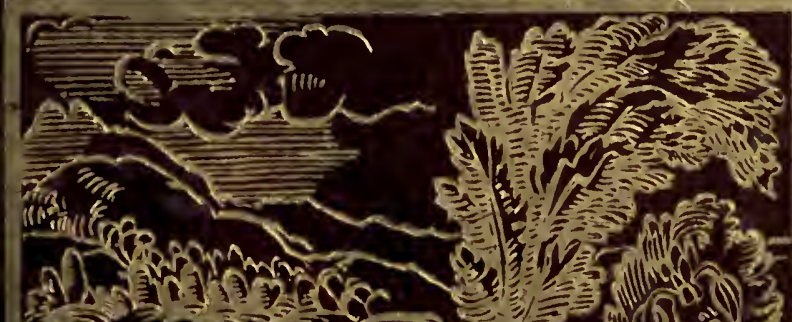

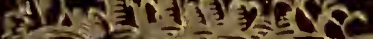

3)
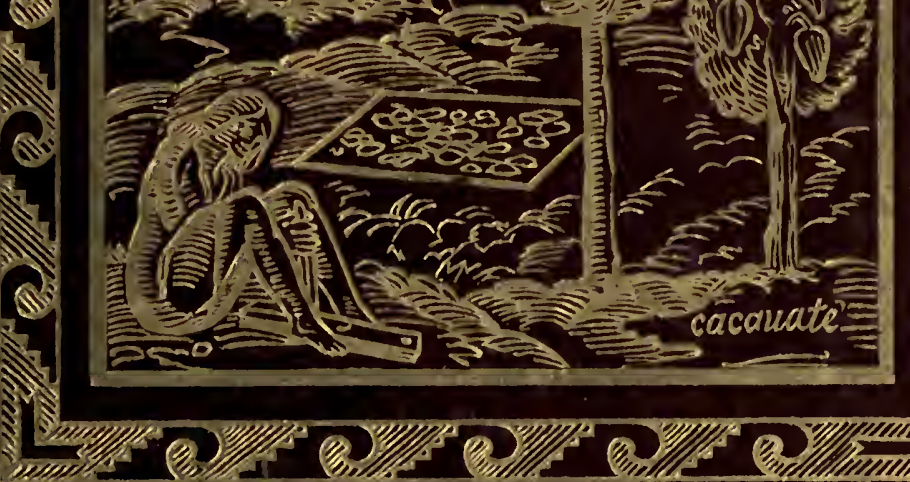

(4)

₹.

Deno

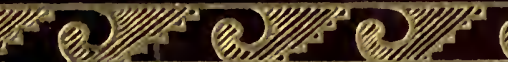


The Bancroft Library

University of California - Berkeley

JOSEPH M. BRANSTEN

COFFEE \& TEA COLLECTION

Acquired in memory of

Joseph M. Bransten 


\section{Digitized by the Internet Archive in 2007 with funding from Microsoft Corporation}





\section{The Chocolate-Plant}

(THEOBROMA CACAO)

ITS PRODUCTS.

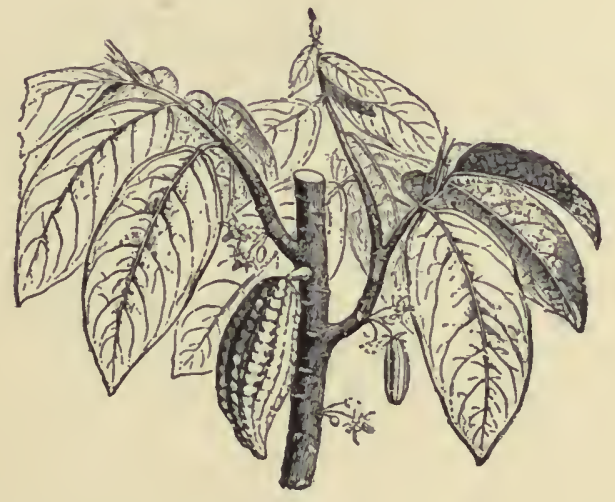

The Fruiting-Stem of a Chocolate-Plant, the Flowers, young Frutt, AND RIPENED POD ALL SPRINGING FROM THE OLdER WOOD.

DORCHESTER, MASS. :

WALTER BAKER AND COMPANY.

1891 . 
Copyright, 1890,

By Walter Baker and Company.

Utnibersity łaress:

John Wilson and Son, Cambridge. 


\section{CONTENTS.}

CHAPTER

PAGE

INTRODUCTORY

5

I. Outline of the Early History of the Chocolate Plant. - Its Primitive Cultivation. - Early Methods of UtilIZING THE SEEds.-- INTROduction OF THE BEverage inTto EUROPE

II. The Natural History of the Chocolate Plant. - The PRESENT RANGE OF THE PLANT UNDER MODERN METHODS OF Cultivation. - Commercial Relations . . . . . . 16

III. The Seeds of the Chocolate Plant, as they appear in Commerce. - Their Microscopic and Chemical Character 23

- IV. Manufacture of Chocolate, and Breakfast Cocoa . . . 26

V. Some Physiological Aspects of Chocolate Seeds. - Value of Chocolate as an Article of Food. - Applications of COCOA-BUTTER •. . . . . . . . . . . . 32

VI. A Few Culinary Relations of Chocolate and Breakfast Cocoa, by Mrs. Ellen H. Richards and Miss Parloa - 35 



\section{INTRODUCTORY.}

FOUR years ago, a convenient handbook on the production and use of various preparations of the chocolate plant was published by our firm. The present work is designed to give, with considerably more detail, some of the interesting facts relative to the early history and cultivation of the chocolate tree, as well as a fuller account of its botany and the chemistry of its products. Since this brochure will doubtless fall into the hands of some who do not have access to the earlier work, we have used with freedom some of the material employed in that; but we hope that these necessary repetitions will increase instead of impair the value of the pages now before the reader.

We trust that this second treatise may be acceptable to our many friends who gave so warm a welcome to the first.

WALTER BAKER AND COMPANY.

DORCHESTER, MassachusetTs, I8gI. 



\title{
THE CHOCOLATE-PLANT.
}

I.

\section{OUTLINE OF THE EARLY HISTORY OF THE CHOCOLATE-PLAN.T.}

\begin{abstract}
A $\mathrm{T}$ the discovery of America, the natives of the narrower portion A of the continent bordering on the Caribbean Sea, were found in possession of two luxuries which have been everywhere recognized as worthy of extensive cultivation; namely, tobacco and chocolate. The former of these has made its way into climates totally unlike that of its early home; the other of these plants, since it cannot bear the low temperature occasionally experienced in our subtropics, is more restricted in its range. The chocolate-plant is confined to the warmer regions of the globe, where it finds the congenial climatic conditions which it enjoyed and still enjoys in its earliest home in Amcrica.
\end{abstract}

The first references to the chocolate-plant and its products are found in the accounts of the explorers and conquerors who followed Columbus. These first descriptions of this singular tree, of its fruits and seeds, of its uses and the methods of cultivation, are remarkably accurate in all essential particulars.

One of the earliest, if not indeed the very earliest, delineations of the chocolate-tree is in a rare volume by Bontekoe. The engraving, which is here reproduced with fidelity, represents the chocolate-tree with its comparatively large fruits or pods borne on 
the main stem. This might be thought at first to be an error of the artist, but it is in fact a rude expression of one of the most remarkable peculiarities of the plant. As will be shown presently, when a fuller description of the plant is given, the fruits are, as a rule, formed on the older parts. Another interesting feature is shown in the engraving: ${ }^{1}$ the chocolate-tree is sheltered by a larger

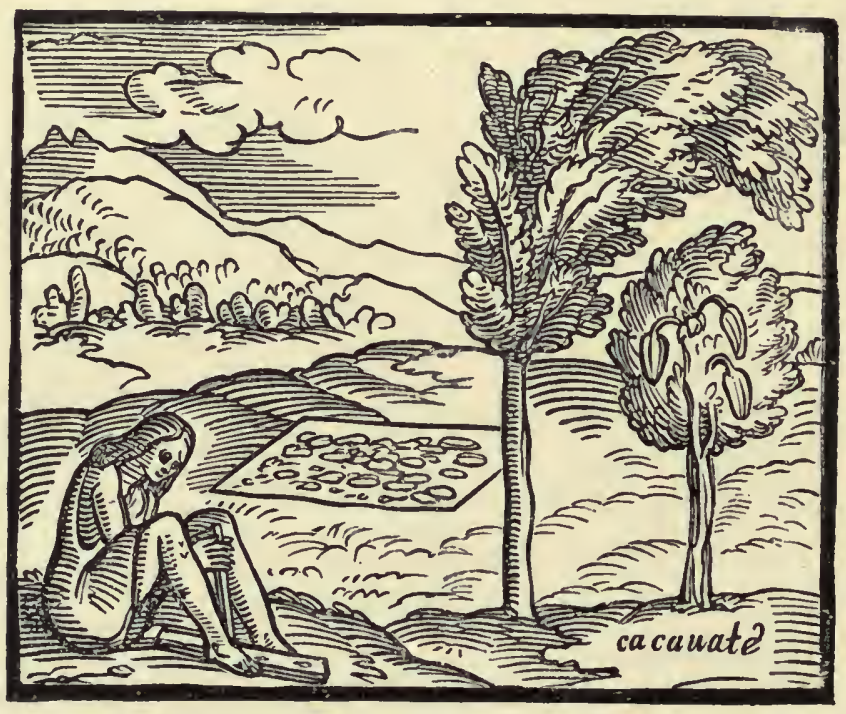

tree of some other kind near it. We shall see shortly, that this practice of planting a sheltering tree to shade the young chocolate plants for a time, is still kept up wherever the plant is successfully cultivated. It is certainly interesting that this point in cultivation, which might easily have been thought to be accidental or local, was delineated more than three centuries ago. By the natives of tropical America, the seeds of the chocolate-plant, which will be more

1 The figure in the left of the foreground is said by Bontekoe to represent the native method of procuring fire by rapidly twirling a pointed stick in a groove of a piece of wood placed on the ground. 
particularly described in a later chapter, were first roasted and then rudely ground. For this purpose they employed the flat or curved surface of the sort of stone used by them to grind their maize, or Indian corn. In the engraving, one of the most simple mills or flat mortars is seen with its roller. The roller was merely a short thick stone of a cylindrical shape, which could be used with one or both hands somewhat after the manner of the common rolling-pin everywhere used in kitchens. By this simple appliance, the crushed seeds were mixed with various ingredients, among which may be mentioned spices of different kinds. A modification of this was later used in Spain. See page 15 .

The drinks made from this coarse chocolate were

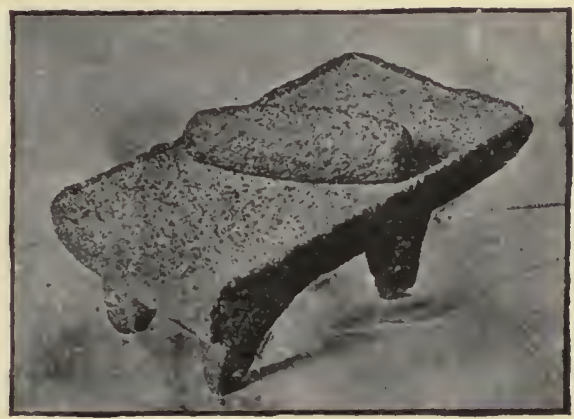

From a Photograph of a Stone Mill, or Flat Mortar. frequently very complex, but the chocolate itself was the chief constituent. It was the custom to beat the mixture into a froth or foam, by means of stirrers, of mallet-like forms; in fact, it is said by some writers that the very name chocolate, is derived from a native word indicating the noise made by the stirring of the beverage.

Thus, Thomas Gage, in his "New Survey of the West Indies," says (under date of 1648 ), "The name chocolatte is an Indian name, and is compounded from atte, as some say, or as others, atle, which in the Mexican language signifieth water, and from the sound which the water (wherein is put the chocolatte) makes, as choco, choco, choco, when it is stirred in a cup by an instrument called a 'molinet,' or 'molinillo,' until it bubble and rise unto a froath." 
The same writer gives us an interesting account of the native method of preparing the drink. From the extract, which is copied without change of the quaint spelling, it will be seen how

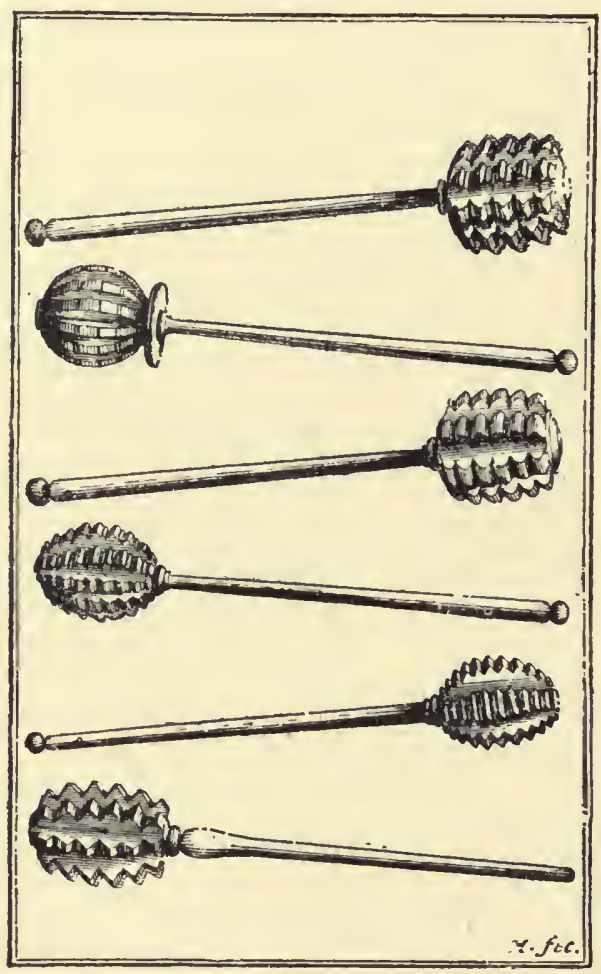

Some of the forms of Chocolate Stirrers ("MOLINETS").

From a treatise published in the Seventeenth Century. wide the use of chocolate was in Europe towards the middle of the seventeenth century :-

"Now, for the making or compounding of this drink, I shall set down here the method. The cacao and the other ingredients must be beaten in a morter of stone, or (as the Indians use) ground upon a broad stone, which they call Metate, and is only made for that use. But first the ingredients are all to be dried, except the Achiotte, with care that they be beaten to powder, keeping them still in stirring that they be not burnt, or become black; for if they be overdried, they will be bitter and lose their virtue. The cinnamon and the long red pepper are to be first beaten with the anniseed, and then the cacao, which must be beaten by

little and little till it be all powdered, and in the beating it must be turned round that it may mix the better. Every one of these ingredients must be beaten by itself, and then all be put into the vessel where the cacao is, which you must stir together with a spoon, and then take out that paste, and put it into the morter, under which there must be a 
little fire, after the confection is made; but if more fire be put under than will only warm it, then the unctuous part will dry away. The Achiotte also must be put in in the beating, that it may the better take the colour. All the ingredients must be searced, save only the cacao, and if from the cacao the dry shell be taken, it will be the better. When it is well beaten and incorporated (which will be known by the shortnesse of it), then with a spoon (so in the Indias is used) is taken up some of the paste, which will be almost liquid, and made into tablets, or else without a spoon put into boxes, and when it is cold it will be hard. .

"Those that make it into tablets put a spoonful of the paste upon a piece of paper (the Indians put it upon the leaf of a plaintin tree), where, being put into the shade (for in the sun it melts and dissolves), it grows hard; and then bowing the paper or leaf, the tablet fals off by reason of the fatnesse of the paste. But if it be put into anything of earth or wood, it stickes fast, and will not come off but with scraping or breaking. 'The manner of drinking it is diverse; the one (being the way most used in Mexico) is to take it hot with Atolle, dissolving a tablet in hot water, and stirring and beating it in the cup, when it is to be clrunk, with a Molinet, and when it is well stirred to a scumme, or froth, then to fill the cup with hot Atolle, and so drink it sup by sup. Another way is that the chocolate, being dissolved with cold water and stirred with the Molinet, and the scumme being taken off and put into another vessel, the remainder be set upon the fire, with as much sugar as will sweeten it, and when it is warme, then to powre it upon the scumme which was taken off before, and so to drink it. But the most ordinary way is to warme the water very hot, and then to powre out half the cup full that you mean to drink; and to put into it a tablet or two, or as much as will thicken reasonably the water, and then grinde it well with the Molinet, and when it is well ground and risen to a scumme, to fill the cup with hot water, and so drink it by sups (having sweetened it with sugar), and to eat it with a little conserve or maple bred, steeped into the chocolatte.

"Besides these ways there is another way (which is much used in the Island of Santo Domingo), which is to put the chocolatte into a pipkin with a little water, and to let it boyle well till it be dissolved, and then 
to put in sufficient water and sugar according to the quantity of the chocolatte, and then to boyle it again untill there comes an oily scumme upon it, and then to drink it.

"There is another way yet to drink chocolatte, which is cold, which the Indians use at feasts to refresh themselves, and it is made after this manner: The chocolatte (which is made with none, or very few, ingredients) being dissolved in cold water with the Molinet, they take off the scumme or crassy part, which riseth in great quantity, especially when the cacao is older and more putrefied. The scumme they lay aside in a little dish by itself, and then put sugar into that part from whence was taken the scumme, and then powre it from on high into the scumme, and so drink it cold. And this drink is so cold that it agreeth not with all men's stomachs; for by experience it hath been found that it doth hurt by causing pains in the stomach, especially to women.

"The third way of taking it is the most used, and thus certainly it doth no hurt, neither know I why it may not be used as well in England as in other parts, both hot and cold; for where it is so much used, the most, if not all, as well in the Indias as in Spain, Italy, Flanders (which is a cold countrey), find that it agreeth well with them. True it is, it is used more in the Indias than in the European parts, because there the stomachs are more apt to faint than here, and a cup of chocolatte well confectioned comforts and strengthens the stomach. For myself I must say, I used it twelve years constantly, drinking one cup in the morning, another yet before dinner between nine or ten of the clock; another within an hour or two after dinner, and another between four and five in the afternoon; and when I was purposed to sit up late to study, I would take another cup about seven or eight at night, which would keep me waking till about midnight. And if by chance I did neglect any of these accustomed houres, I presently found my stomach fainty. And with this custome I lived twelve years in those parts healthy, without any obstructions, or oppilations, not knowing what either ague or feaver was."

After its introduction into Europe from America, chocolate was used at first only as a luxury, but it has steadily advanced 


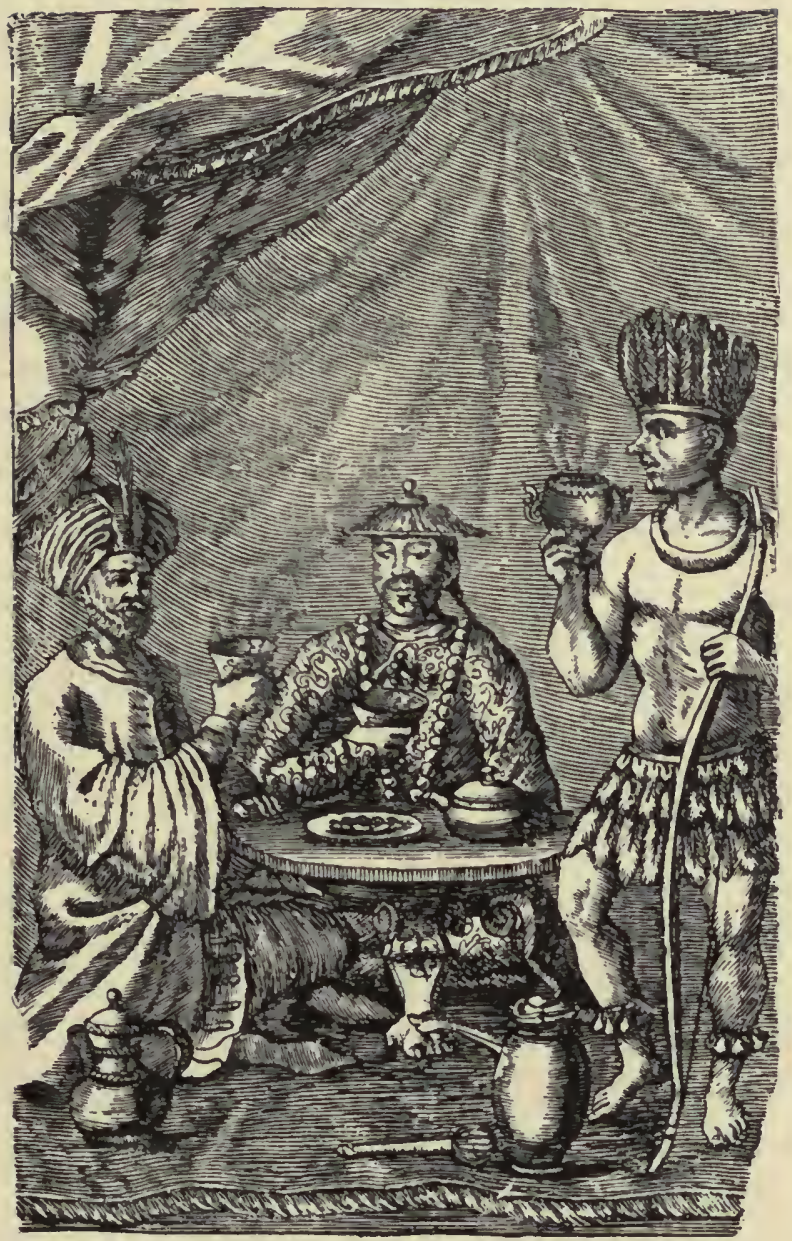

Frontispiece of ONE of the Earliest Works on Chocolate.

in popular esteem until it is now recognized as one of the necessaries of life.

It would be interesting to speculate as to the accidents which led to the original use of such beverages as coffee, tea, and chocolate. The earliest employment of the two former is veiled 
in as cleep a mystery as that which surrounds the chocolateplant. All were used at the outset by what we have been accustomed to call the uncultivated races of mankind, but we cannot surmise what first attracted their attention to these plants. One can only say that by the natives of lands where the plants grow naturally, they have all been used from time immemorial, and that all three are welcome gifts from a rude state of civilization to the highest which exists to-day. By the savages and the Aztecs of America, by the roving tribes of Arabia, and by the dwellers in the farther East, the virtues of these three plants were recognized long before any one of them was introduced into Europe.

There is reason to believe that long before the discovery of America, Tea and Coffee had been vaguely known to travellers in the Orient, as curiosities, much as we to-day regard the Kolanut and Maté, but neither Tea nor Coffee was then employed as a beverage anywhere in Western Europe. In fact, all trustworthy evidence in the case leads us to a surprising conclusion, namely, That Chocolate was the first of these beverages to attract the attention of Europeans. This beverage rapidly made its way throughout Europe, beginning from Spain and Portugal, whither its discoverers had brought it. The other beverages, Tea and Coffee, soon followed; and after a short time became associated together in popular regard.

In a duodecimo work published in 1685, and now very rare, the beverages derived from these three plants are described in a clear and forcible manner. The reproduction of the frontispiece of this book, given above, shows how intimate the association of these beverages was regarded even two centuries ago. It is interesting to observe the distinction made by the artist in the receptacles and cups for holding these three different drinks. 
On the floor, near the vase, is seen one of the chocolate-stirrers described on page 10.

At the outset the manufacture of chocolate in Europe was carried on with substantially the same appliances as those used by the natives. A curious indication of this is afforded by the engraving, which shows that the Portuguese mill was to all intents modelled after that used by the Mexicans.

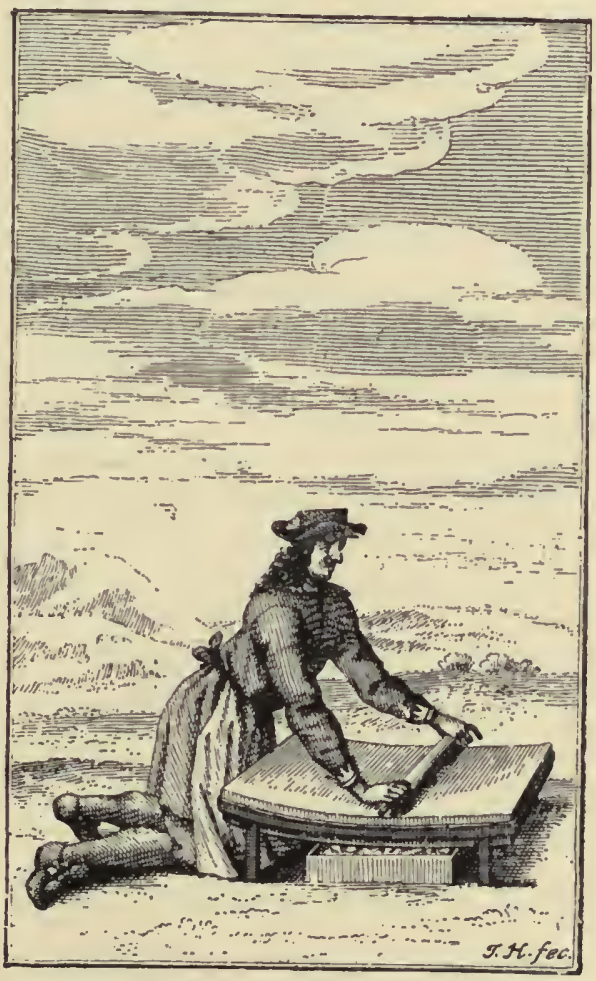

Chocolate-Grinding in the Seventeenth Century.

From an early engraving. 


\section{II.}

THE NATURAL HISTORY OF THE CHOCOLATEPLANT.

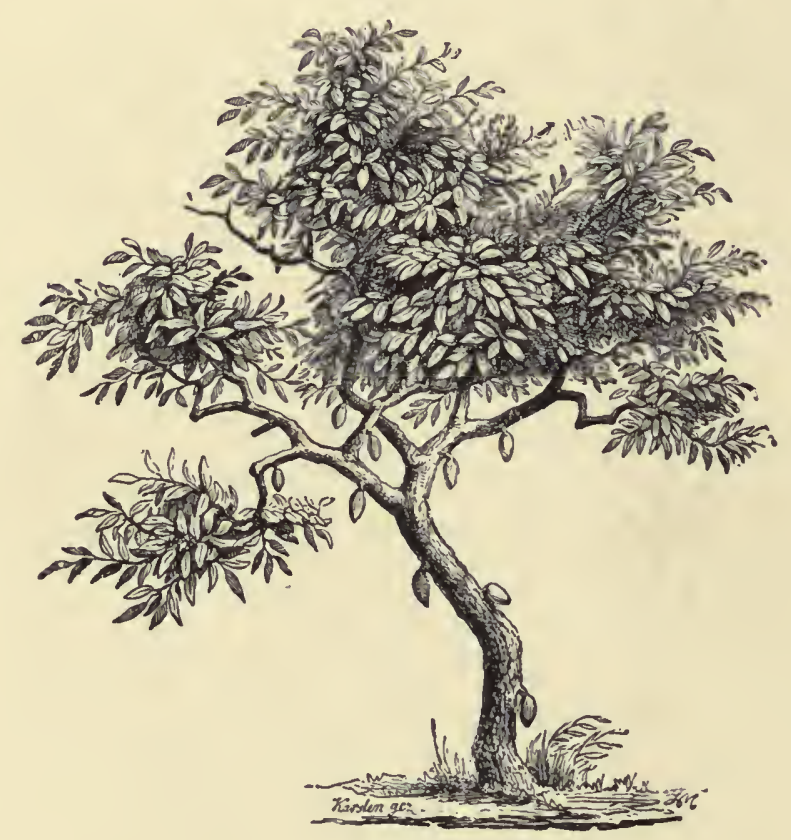

Theobroma Cacao.

'THE chocolate plant is known to botanists as Theobroma 1 Cacao. The first or generic word in this name means food of the gods. The genus contains six species, only one of which is generally cultivated. It is probable, however, that some of the seeds which find their way into commerce are yielded by other and wild species. It is, moreover, more than 


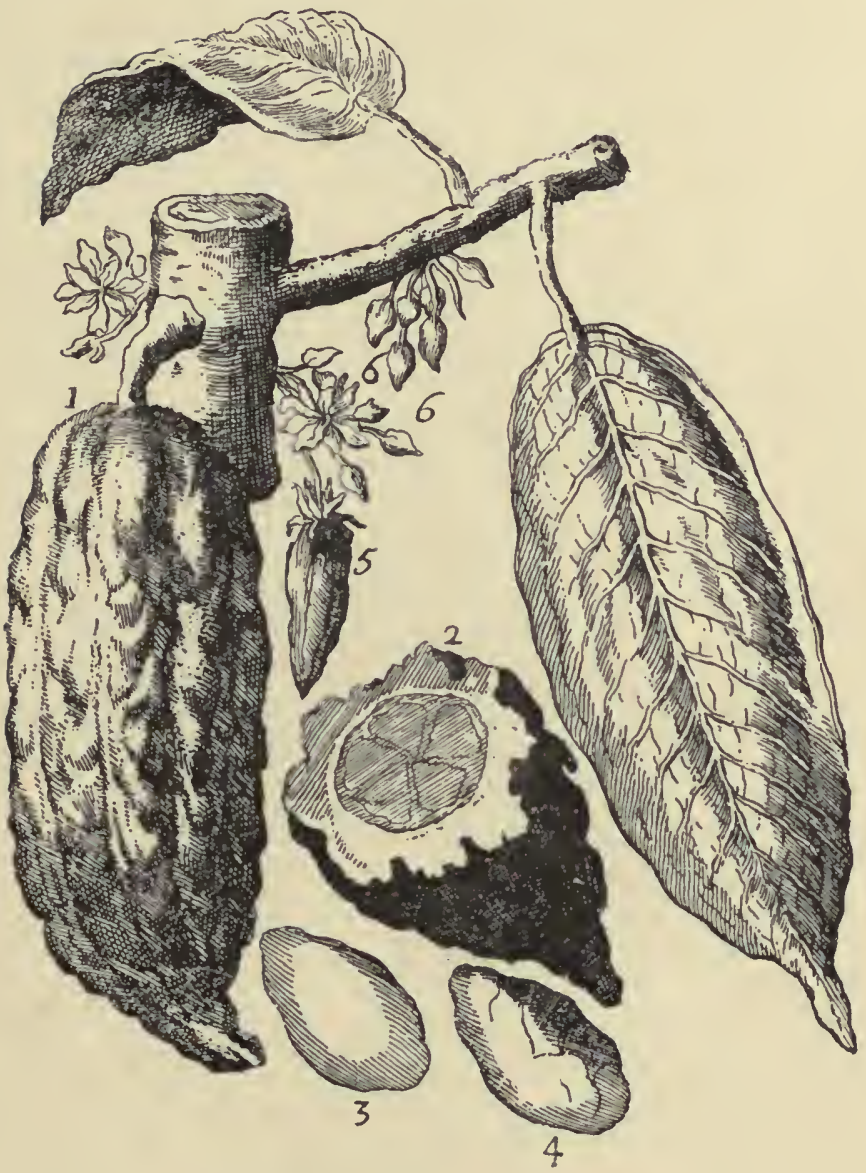

Flowers, Fruit, and Seeds of Theobroma.

From an old engraving.

likely that among the numerous varieties of Theobroma Cacao now cultivated there may be some hybrids between the different forms.

The plant belongs to the Sterculiaceæ, a natural order containing forty-one genera and five hundred and twenty species. The general habit of the tree is well shown in the engraving. 


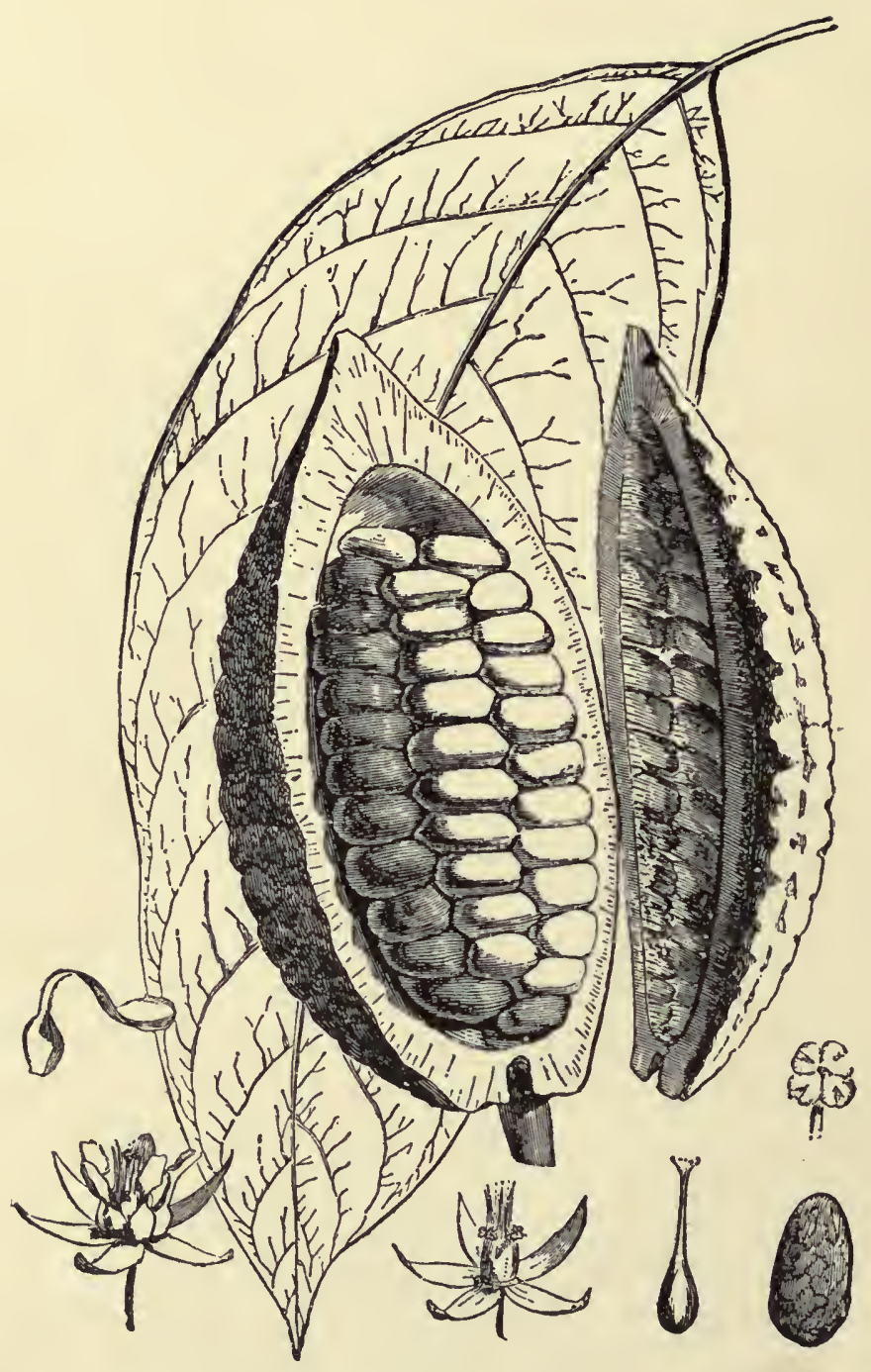

Flowers, Fruit, and Seeds of Theobroma.

From a recent drawing. 
The seeds of the plant are borne in pods, represented in the illustrations on pages $I 7$ and 18 , the former taken from one of the early works on the subject. No. I in the first engraving exhibits the ripened pod, 5 and 6 the fruits in different stages of growth. No. 2 shows the pod cut open and displays some of the seeds, while 3 and 4 are the seeds themselves, - the former in its natural state, the latter with the seed-coats removed.

The pod is irregular and angular, much like some forms of cucumbers, but more pointed at the lower extremity, and more distinctly grooved. It measures in length nine inches to a foot, or even more, and about half as much in diameter. The color, when young, is green, becoming later dark yellow or yellowish brown. The rind is thick and tough. The pod is filled with closely packed "beans," or seeds, imbedded in a mass of cellular tissue, sometimes of pleasant subacid taste. The seeds are about as large as ordinary almonds, whitish when fresh, and of a disagreeable bitter taste. When dried they become brown.

The fruits are about four months in ripening; but they appear and mature the whole year through. In point of fact, however, there are chief harvests, usually in early spring, but this is different for different countries.

The following extract from a comparatively recent consular report gives a clear idea of the modern method of cultivating the plant in some parts of South America. The extract was given in our former edition, but it is thought best to transcribe it here.

"The tree grows to the average height of thirteen feet, and from five to eight inches in diameter, is of spreading habit and healthy growth, and although requiring much more care and attention than the coffee-tree, yet its equally reliable crops require comparatively little labor in properly preparing for the market. 
". . . There are two varieties of the cocoa-tree cultivated in Venezuela, known as El Criollo and El Trinitario, respectively, the former of which, though not so prolific, nor as early fruiting as the latter, is yet superior to it in size, color, sweetness, and oleaginous properties of the fruit, and in the fact that it always finds ready sale, while the latter is often dull or neglected. The difference in price of the two varieties is also marked, the former being quoted at $\$ 28$ to $\$ 30$ per fanega (I Io pounds), while the latter commands approximately half that price.

"While coffee can be successfully cultivated under a temperature of 60 degrees F., the cocoa-tree, for proper development and remunerative crops, requires a temperature of 80 degrees $\mathrm{F}$.; hence the area of the cocoa belt is comparatively restricted, and the cocoa-planter presumably has not to fear the fierce competition that he has encountered in the cultivation of cotton and coffee. Besides the condition of temperature above stated, this crop needs a moist soil and humid atmosphere; and so the lands along the coast of the Caribbean sea, sloping from the mountain-tops to the shore, bedewed by the exhalations of the sea and irrigated by the numerous rivulets that course down the valleys, are found to be, in all respects, well adapted to the profitable cultivation of cocoa. And while the lands in the interior possessing facilities for irrigation may be said to be equally as good for the purpose, yet the absence of roads, and the consequently difficult transportation of produce on the backs of donkeys over rugged mountain paths, materially reduce the profits on the crop before it reaches the market.

"A cocoa plantation is set in quite the same manner as an appleorchard, except that the young stalks may be transplanted from the nursery after two months' growth. No preparation of the soil is deemed necessary, and no manures are applied. The young trees are planted about fifteen feet equidistant, which will accommodate two hundred trees to the acre. Between rows, and at like spaces, are planted rows of the Bucare, a tree of rapid growth, that serves to shade the soil as well as to shield the young trees from the torrid sun. Small permanent trenches must be maintained from tree to tree throughout the entire length of the rows, so that, at least once in the week, the stream, 
descending from the mountains, may be turned into these little channels and bear needful moisture to trees and soil. At the age of five years the plantation begins to bear fruit, and annually yields two crops, that ripening in June being termed the crop of San Juan, and that maturing at Christmas being known as the crop of La Navidad. The average age to which the trees attain, under proper care, may be estimated at forty years, during which period it will give fair to full crops of fruit; but of course it must be understood that, as in our fruit orchards, a new tree must be set from time to time to replace one that may be decayed or blighted. After careful inquiry it may be safely stated that the average crop of the cocoa plantation at ten years of age, and under a proper state of cultivation, will amount to five hundred or six hundred pounds per acre."

The method of preparing the fruit for shipment is thus described in the "Encyclopædia Britannica":-

"In gathering, the workman is careful to cut down only fully ripened pods, which he adroitly accomplishes with a long pole armed with two prongs, or a knife at its extremity. The pods are left in a heap on the ground for about twenty-four hours; they are then cut open and the seeds are taken out and carried in baskets to the place where they undergo the operation of sweating or curing. There the acid juice which accompanies the seeds is first drained off, after which they are placed in a sweating-box, in which they are enclosed and allowed to ferment for some time, great care being taken to keep the temperature from rising too high. The fermenting process is, in some cases, affected by throwing the seeds into holes or trenches in the ground, and covering them with earth or clay. The seeds in this process, which is called "claying," are occasionally stirred to keep the fermentation from proceeding too violently. The sweating is a process which requires the very greatest attention and experience, as on it, to a great extent, depends the flavor of the seeds and their fitness for preservation. The operation varies according to the state of the weather, but a period of about two days yields the best results. Thereafter the seeds are exposed to the sun for drying, and those of a fine 
quality should then assume a warm, reddish tint, which characterizes beans of a superior quality."

Cocoa-beans are derived chiefly from the following sources, here arranged alphabetically. A recent author has classified them under two heads, unfermented and fermented; but this classification is very misleading, since it happens that from a few of the places mentioned variable proportions of both sorts are brought to market. Ariba (Ecuador), Bahia (Brazil), Caracas (Venezuela), Cayenne (French Guiana), Ceylon, Guatemala, Haiti, or Port au Prince, Java, Machala, or ordinary Guayaquil (Ecuador), Maracaiba (Colombia), Mararion (Brazil), St. Domingo, Surinam (Dutch Guiana), Trinidad (W. I.), from Africa, the Seychelles, Martinique, and Bourbon, variable amounts are beginning to appear as regular products. It is generally understood that some of the best sorts of South American cocoa are consumed at home and do not find their way, in definite quantities, or as a stated supply, to any foreign ports. Among these are Soconusco and Esmeraldas. At the last French exposition these and other very fine sorts from Venezuela and Ecuador were exhibited. New fields are being opened up in many directions to meet the increasing demand for the product. 


\section{III.}

THE SEEDS OF THE CHOCOLATE-PLANT AS THEY APPEAR IN COMMERCE. THEIR MICROSCOPIC AND CHEMICAL CHARACTERS.

THE seeds of the chocolate-plant are brought into the market in color and somewhat in texture. It is not uncommon to find the external surface of the bean more or less covered with a thin irregular layer of attached earth, but this is generally pretty well cleared off during the transportation.

Upon the color of shell and kernel, the relative brittleness, the flavor, and the odor, depends the market value of the seeds.

The dried seeds have a papery, brittle shell, which is very smooth on the inside, but on the outside exhibits, under the microscope, a few short hairs and round excrescences. But these are mostly lost by the rough handling and by the attrition of the seeds with one another during transportation. The kernel consists of two large cotyledons or seed-leaves, reddish-gray or reddishbrown, with a shining, oily surface; the whole crushing rather easily into a loose mass of fragments. The kernel, when dry, has a minute, tough, almost stony radicle which separates easily from the cotyledons. Microscopic examination shows that the cells of the seed-leaves contain albumen, oily matters, - sometimes in a crystalline condition, - crystals of an entirely different shape, starch, coloring substances in special receptacles known as pig- 
ment-cells, and ducts with spiral markings. The starch grains do not have any very characteristic form or markings: they are generally spherical and simple. The only peculiarity worth mentioning, is the relative slowness with which they are acted on by hot water and by iodine. The coloring substances are mainly of a carmine or violet color, and are distinguished by the change of shade when an alkali is added, becoming thereby darker.

These are the only structural elements which a pure powder or paste of chocolate should show under the microscope. Any other substances must be recognized as accidental or intentional additions.

All seeds of whatever kind contain, as a part of their substance, the matter of which cell-walls are made; namely, cellulose. The percentage differs in different seeds, in those of the chocolateplant being about three in the hundred. Cellulose has the same chemical composition as starch; but its physical properties are not the same as those of starch, among which may be mentioned its entire insolubility in boiling water.

Starch forms, on an average, eight to ten per cent of chocolateseeds. It consists of minute spherical grains, not distinguishable from that found in many other kinds of seeds. Traces of gum and of other allied bodies are also present in the seeds.

A.lbuminoids, or substances resembling, in a general way, the albumin of egg, occur in chocolate-seeds as they do in other seeds, and in a somewhat higher amount than in certain other cases in which the seeds are used as food. The percentage ranges from about fifteen to twenty, depending on the variety. These albuminoids are compounds of nitrogen, and are extremely nutritious. In the seeds they occur in a readily assimilable form, fit for digestion. Their peculiar relations as flesh-formers are referred to in the section treating of the physiology of chocolate-seeds. 
Cacao-red occurs as a coloring matter in small amount. It is rendered dark by alkalies.

Theobromine, the active principle of the cocoa-bean, constitutes less than one per cent of the weight of the seeds, but it varies greatly in amount in different seeds, ranging from $\frac{30}{100}$ of one per cent in some, to a trifle over one per cent in others.

The ash left on completely burning cocoa-beans is not far from four per cent. Its composition is substantially that of the ash of seeds of other plants.

Cocoa-butter, or oil, constitutes not far from fifty per cent of good cocoa-beans. The oil is remarkable for its freedom from rancidity and its very bland character. Its uses are innumerable.

The following averages of many analyses by a leading recent authority may be of interest :-

UNROASTED.

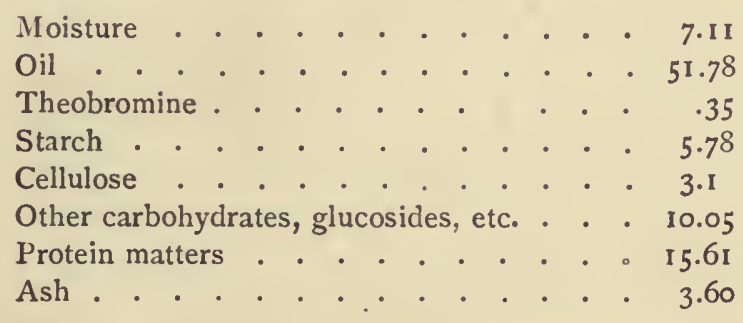

ROASTED.

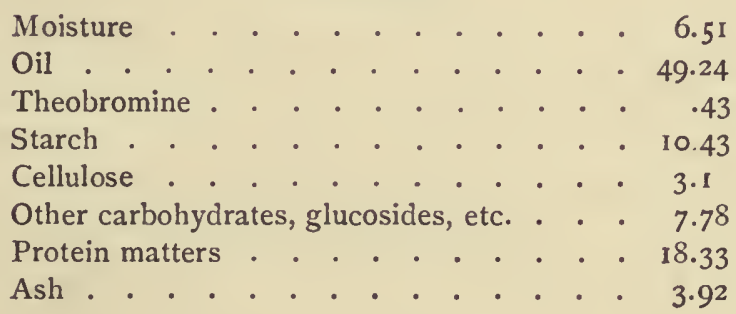


IV.

\section{MANUFACTURE OF CHOCOLATE AND BREAKFAST COCOA.}

WE have already called attention to the simple process by which the natives of Central America prepared a nutritious beverage from the seeds of the chocolate-plant. The essential features of this process, modified and greatly improved by modern science, are worthy of consideration at this time.

The selected cocoa-beans are first cleaned from the dust and attached particles which have come from various sources during the fermentation of the seeds. The machines for cleaning the beans are very ingenious and effective, removing from the seedcoat every trace of foreign matter.

The cleaned seeds are next roasted in the most careful manner, every precaution being taken to secure a uniform effect through the whole mass. During the roasting the seeds change color somewhat and become more or less modified in taste. In underroasted seeds the flavor is not fully developed, while in overroasted seeds the pleasant taste is likely to become greatly impaired, or it may even be wholly replaced by a bitter and harsh flavor. These relations of color and taste to the roasting of the seeds make this portion of the manufacture one of the most delicate processes from beginning to end.

By the roasting the shell becomes more readily detachable, and its complete removal is the next step. The crushing of the seeds into small fragments is easily accomplished; and this is 
followed by a thorough winnowing, by which the lighter shells are carried away by themselves, leaving the clean fragments of the roasted seeds ready for further manipulation.

Among the fragments can be detected minute and very tough bits of tissue. These bits are the hardened germs, or rather portions of the germs, and these are separated from the rest by an apparatus of much simplicity and efficiency.

The clean shells are usually placed at once in packages for transportation. They are extensively used for the domestic preparation of a wholesome and very low-priced drink. This beverage contains a fair proportion of the active principle of the chocolateseeds themselves, and the flavor is suggestive of chocolate.

The cleaned fragments constitute the so-called "cocoa-nibs" of some foreign markets, and in this state they are used for the preparation of a simple decoction. But in this form they require to be boiled a good while for the development of flavor, and it is therefore better to have them treated beforehand in order to reduce the time of boiling; and this is all the more necessary, since during the long boiling a part of the more delicate aroma peculiar to chocolate-seeds is apt to be dissipated.

We are next to trace these fragments, through the chocolatemill, and afterwards follow similar fragments through the cocoafactory.

In the preparation of chocolate, the fragments are ground by a complicated mechanism until they attain the greatest degree of fineness, and constitute a perfectly homogeneous mass or paste. If the chocolate is to be a plain chocolate, it is to receive its delicate flavoring and then go directly into the moulds for shaping it. Every step of the process has to be watched with the most assiduous care. When the chocolate is formed and properly cooled, it is wrapped and packed for the market. 
But if the chocolate is to be sweetened, a definite amount of the purest sugar, previously pulverized, is to be added, the whole ground and commingled, the proper flavoring of pure vanilla added, and the semi-solid mass formed in moulds as before. After being moulded it is sent to the packing-room and wrapped.

The variations in the process are innumerable, but all of them are comparatively unimportant when taken singly; the skill in the manufacture requires that each of these slight changes should be made at just the right time and in the right way. In the manufacture of Walter Baker and Co.'s chocolate, this skill has become developed to a very high degree during the hundred years of success. That the firm is ready to avail itself of every appliance known in modern manufacture, is seen by their adoption of the complicated machinery illustrated on page 29. This chocolatemachine has a capacity of five tons of pure chocolate daily. It is accessible to visitors, who may apply at the office in Dorchester for permission to see it in operation.

It is unnecessary to detail the steps of manufacture of many of the chocolate specialties of the firm.

We turn now to the consideration of breakfast cocoa.

The manufacture of breakfast cocoa is based upon two important factors : first, the removal of a definite portion of the cocoaoil from the roasted seeds; and second, increasing the miscibility of the powdered seeds by securing the greatest practicable degree of fineness. 


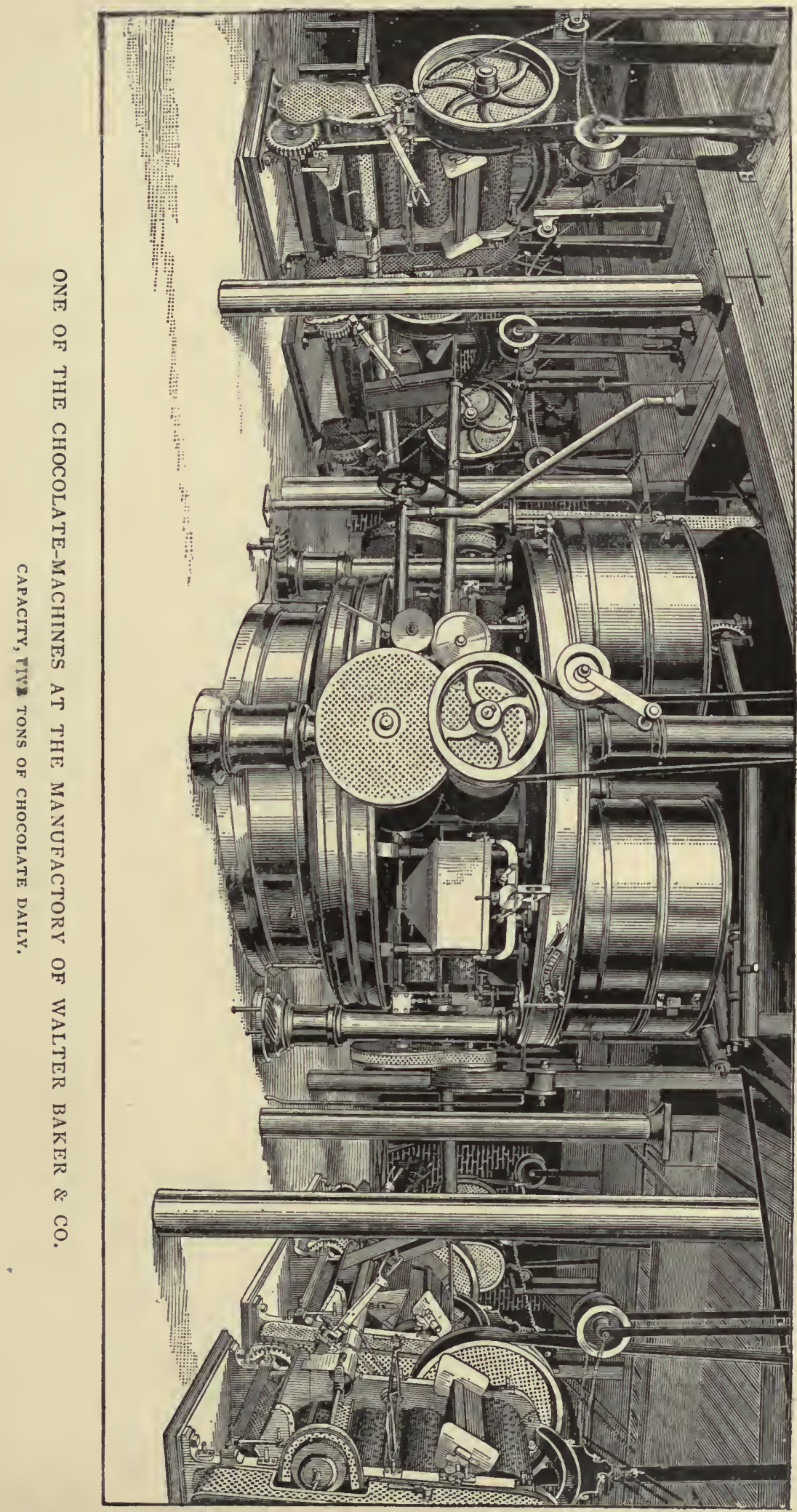


While the oil of the chocolate-seed is perfectly wholesome, there are some persons who find in the percentage natural to the seeds a too large amount for easy digestion. The removal

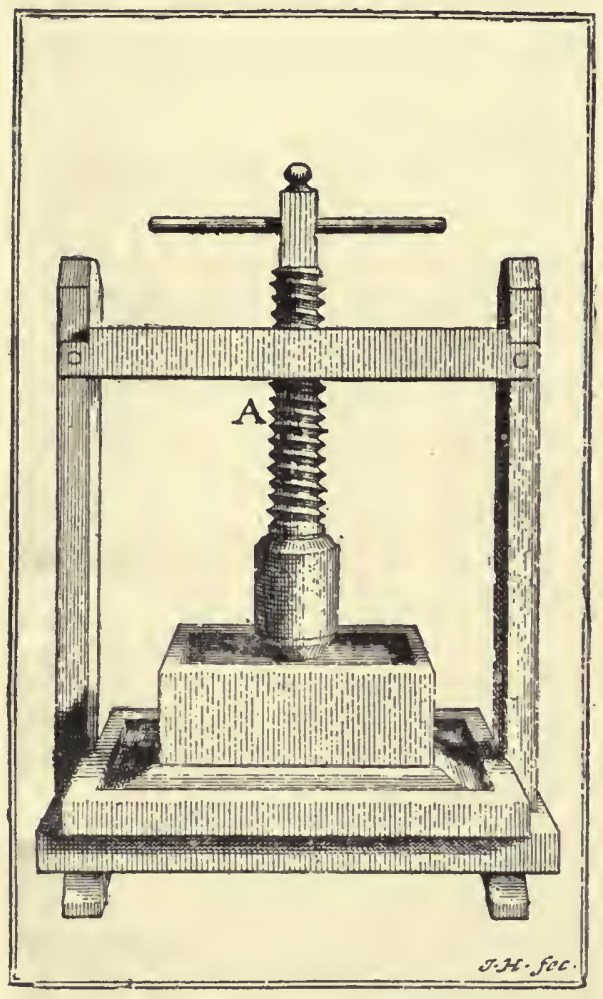
of a part of this, which might with propriety be called an excess of the oil, was practised even in very early days, as is seen in the cut herewith given, taken from an old work on the subject. The present method of extracting the oil is not essentially different, save in a few particulars, from that here figured, and therefore need not be described in detail.

The method of manufacture is substantially as follows: the ground fragments of roasted seeds are subjected to pressure, and with the result of withdrawing just as much oil as the manufacturers desire to abstract. The pressed mass is, in the most successful process, treated mechanically in such a manner as to divide and subdivide the minute particles until they are capable of passing through a sieve having several thousand meshes to the square inch. But such pulverization as this would, under ordinary circumstances, reduce the mass to a dull and unattractive powder. In the process devised by the firm of Walter 
Baker and Co., this high degree of fineness is secured without any loss of brilliancy in the powder, - the color being of the bright-red which is not only attractive in appearance, but when conjoined with the natural chocolate odor and flavor is characteristic of absolutely pure cocoa of the highest grade.

It is instructive to compare such cocoa with the cocoas prepared by what is known in chemical technology as the chemical process. The latter are prepared by treatment with alkaline matters which act on the coloring substances in the seeds, increasing the apparent effect of hot water when the latter is added. In chemically prepared cocoas, the exquisite natural odor and flavor of pure cocoa-seeds have been diminished or wholly lost by the severe treatment to which the materials have been subjected. In some cases the loss of the natural flavor is sought to be partially supplied by the use of fragrant gums, wholly foreign to the natural product.

The detection of these admixtures is generally easy. Comparison with the well-known pure breakfast cocoa of Walter Baker and Co. will reveal at once the vast superiority of a product which has not been treated by chemicals, but which contains only the finest possible powcler of the best chocolate-seeds freed from the excess of oil. The exquisite flavor and odor of the pure product are due wholly to the seeds themselves, since absolutely no foreign matter is added from first to last. Walter Baker and Co.'s breakfast cocoa can be used by students of the microscope and of chemistry as a perfect type of the highest order of excellence in manufacture. The enormous increase in consumption of Baker's cocoa and chocolate indicates that our discriminating public appreciate a thoroughly good article when they see it. 


\section{V.}

SOME PHYSIOLOGICAL ASPECTS OF CHOCOLATESEEDS. - VALUE OF CHOCOLATE AS AN ARTICLE OF FOOD.

THE seeds of plants contain a germ, or embryo, together with

a certain amount of food. As soon as the germ sprouts, the food, or a good part of it, is consumed by the seedling, being used by it in the formation of new parts, such as roots and leaves by which the materials for more food can be obtained from the soil and air. Now it happens that the food of plants is pretty much the same as the food of animals, although there is this marked difference in the manner of procuring it: plants can construct their own food from inorganic or mineral matters taken from the earth and atmosphere, while animals, even those which are most like plants, must have their supply of food from organic nature.

Since, then, plants prepare the food which animals are to use (of course flesh-eating animals use their plants, so to speak, at second-hand), it comes to pass very naturally that the food in a good many seeds has been recognized from early times as very useful food for man. Thus the cereals - wheat, maize, oats, barley, and rice-are the seeds of grasses; and there are many other seeds, such as beans, peas, buckwheat, and so on, which have been appropriated as food by man from remote antiquity. But the seeds of some plants are unfit for human food, owing to disagreeable properties which they possess; while there are a few which stand on the very edge of the limit of foods, and have been used in time of scarcity. 
The seeds of at least two plants are used as important adjuncts to our list of foods, and can be enumerated among foods without any impropriety. These are coffee and cocoa. They contain nutritive properties, - the latter in very much higher degree than the former, - and they possess also peculiar constituents which entitle them to rank as luxuries. These peculiar constituents are (I) flavoring matters, and (2) an active principle. But, either from its constitution or from its association in the seed, the active principle of coffee, although it has nearly or quite the same ultimate composition as the active principle of cocoa, is unlike it in its effects. The active principle of cocoa is substantially free, as used in its preparations, from any undesirable effects on the nervous system. This active principle of cocoa is Theobromine.

The essentials of a perfect food are (I) a certain amount of carbohydrates, (2) of albuminoids, and (3) certain mineral matters, these latter being substantially the same in all seeds used as food. In cocoa these three groups are combined in proper proportion to constitute a complete food, but there is superadded the active principle, Theobromine, which places it at once in the class of luxuries as well as of necessary foods.

When cocoa-seeds are prepared properly for food, without doing violence to the chemical relations of the different components, a comforting nutritive article of the highest value is obtained. This ideal method of preparation is not a chemical torturing by the addition of foreign ingredients, as in the alkali process, but it consists in the complete unlocking, by perfectly natural, mechanical means, of all the virtues of the seeds. We do not try to render the albuminoids of wheat and other grains soluble by means of ammonia, soda, or potash, nor do we think it desirable to increase the solubility of the albuminoids of egg and meat by 
adding caustic or carbonated alkalies to them before they are used. And yet chemical processes analogous to these have been devised and are sometimes used with regard to cocoa. In most cases these added substances are detected in the increased amount of mineral matters found in the ash after burning the preparation. The amount of ash in pure cocoa is about four per cent. Any appreciable amount above this may be attributed to the admixture of mineral matters used in the preparation.

The oil in pure chocolate-seeds is about fifty per cent of the whole weight. Although the oil is exceedingly bland and free from rancidity, it has been found expedient in some cases to withdraw a part of this oil, leaving a smaller amount in the product. This is the method pursued in the manufacture of the powdered cocoas. With this reduction in the quantity of oil, the resultant beverage is less likely to disagree with delicate digestion.

It is in all cases of the first importance to obtain only pure cocoa of the highest quality, free from any admixture of foreign matter, such as the alkalies or their carbonates; and further, the product ought to be of the greatest degree of fineness. With regard to the flavors added to chocolate, it is perhaps needless to say that they should be of the utmost degree of purity. This is especially true of vanilla, which owing to its high cost is frequently replaced by artificial flavors. There is, in one respect, a notable difference between sweet chocolate and cocoa: the former may be flavored, the latter should never be.' A pure cocoa must be absolutely dependent on its own delicious, natural odor and flavor. No addition of any substance of any kind is admissible. 


\title{
SUGGESTIONS
}

\author{
RELATIVE TO \\ THE COOKING OF CHOCOLATE AND COCOA. \\ BY MRS. ELLEN H. RICHARDS, \\ Of the Massachusetts Institute of Technology.
}

HE flavor of the cocoa-bean seems to be almost universally
liked, and the use of the various preparations made from it is constantly increasing. From the sweet chocolate with which the traveller now provides himself in all journeys in which the supply of food is doubtful either in quantity or quality, to delicate coloring and flavoring of cakes and ices, nearly all kinds of culinary preparations have benefited by the abundance of this favorite substance.

In these forms, chocolate is used in a semi-raw state, the bean having been simply roasted at a gentle heat, ground, and mixed with sugar, which holds the fat. By varying the quantity of the chocolate to be mixed with the ingredients of the cake or ice, an unlimited variety of flavors can be obtained.

In preparing it as a beverage for the table a mistake has been frequently made in considering chocolate merely as a flavor, an adjunct to the rest of the meal, instead of giving it its due prominence as a real food, containing all of the necessary nutritive principles. A cup of chocolate made with sugar and milk is in itself a fair breakfast.

There is much to be said in favor of preparations of the whole bean which secure all of the valuable nutrition contained in 
this "food for the gods," and rightly understood, it is possible to make them more important articles of diet than they now are. But since the large percentage of fat seems to require correspondingly large quantities of sugar to render the beverage palatable, and this very rich, sweet drink soon cloys if made strong enough to be nutritious, it is, fortunately, possible to extract the larger part of the fat without injury to the flavor so characteristic of chocolate. In this form, called cocoa, less sugar and more milk are needed, and the resulting beverage suits even delicate stomachs, and is yet of high food value.

It is the object of all cooking to render raw material more palatable and more nutritious, and therefore more digestible. The cooking of cocoa and chocolate is no exception to this rule. Certain extractive principles are soluble only in water which has reached the boiling-point; and the starch, which the seed contains, is swollen only at this temperature.

Chocolate or cocoa is not properly cooked by having boiling water poured over it. It is true that as the whole powder is in suspension and is swallowed, its food material can be assimilated as it is when the prepared chocolate is eaten raw; but in order to bring out the full, fine flavor and to secure the most complete digestibility, the preparation, whatever it be, should be subjected to the boiling-point for $\dot{a}$ few minutes. In this all connoisseurs are agreed. 


\section{R E C E I P T S.}

BY MISS PARLOA.

\section{PLAIN CHOCOLATE.}

For six people, use one quart of milk, two ounces of W. Baker \& Co.'s No. I chocolate, one tablespoonful of corn-starch, three tablespoonfuls of sugar, and two tablespoonfuls of hot water.

Mix the corn-starch with one gill of the milk. Put the remainder of the milk on to heat in the double-boiler. When the milk comes to the boilingpoint stir in the corn-starch, and cook for ten minutes. Have the chocolate cut in fine bits and put it in a small iron or granite-ware pan; add the sugar and water, and place the pan over a hot fire. Stir constantly until the mixture is smooth and glossy. Add this to the hot milk and beat the mixture with a whisk until it is frothy. Or the chocolate may be poured back and forth from the boiler to a pitcher, holding high the vessel from which you pour. This will give a thick froth. Serve at once.

If you prefer not to have the chocolate thick, omit the corn-starch.

\section{CHOCOLATE MADE WITH CONDENSED MILK.}

Follow the rule for plain chocolate, substituting water for the milk, and adding three tablespoonfuls of condensed milk when the chocolate is added.

\section{CHOCOLATE; VIENNA STYLE.}

Use four ounces of vanilla chocolate, one quart of milk, three tablespoonfuls of hot water, and one tablespoonful of sugar.

Cut the chocolate in fine bits. Put the milk on the stove in the doubleboiler, and when it has been heated to the boiling-point, put the chocolate, 
sugar, and water in a small iron or granite-ware pan and stir over a hot fire until smooth and glossy. Stir this mixture into the hot milk, and beat well with a whisk. Serve at once, putting a tablespoonful of whipped cream in each cup and then filling up with the chocolate.

The plain chocolate may be used instead of the vanilla, but in that case use a teaspoonful of vanilla extract and three generous tablespoonfuls of sugar instead of one.

\section{BREAKFAST COCOA.}

Breakfast cocoa is powdered so fine that it can be dissolved by pouring boiling water on it. For this reason it is often prepared at the table. A small teaspoonful of the powder is put in the cup with a teaspoonful of sugar; on this is poured two-thirds of a cupful of boiling water, and milk or cream is added to suit. the individual taste. This is very convenient; but cocoa is not nearly so good when prepared in this manner as when it is boiled.

For six cupfuls of cocoa use two tablespoonfuls of the powder, two tablespoonfuls of sugar, half a pint of boiling water, and a pint and a half of milk. Put the milk on the stove in the double-boiler. Put the cocoa and sugar in a saucepan and gradually pour the hot water upon them, stirring all the time. Place the saucepan on the fire and stir until the contents boil. Let this mixture boil for five minutes; then add the boiling milk, and serve.

A gill of cream is a great addition to this cocoa.

\section{CHOCOLATE CAKE.}

For two sheets of cake use three ounces of IV. Baker \& Co.'s No. I chocolate, three eggs, one cupful and three-fourths of sifted pastry flour, one cupful and three-fourths of sugar, half a cupful of butter, half a cupful of milk, half a teaspoonful of vanilla extract, one teaspoonful and a half of baking powder.

Grate the chocolate. Beat the butter to a cream and gradually beat in the sugar. Beat in the milk and vanilla, then the eggs (already well beaten), next the chocolate, and finally the flour, in which the baking powder should be mixed. Pour into two well-buttered shallow cake-pans. Bake for tiventy-five niinutes in a moderate oven. Frost or not; as you like. 


\section{VANILLA FROSTING.}

Break the white of one large egg into a bowl, and gradually beat into it one cupful of confectioner's sugar. Beat for three minutes, add half a teaspoonful of vanilla extract, and spread thinly on the cakes.

\section{CHOCOLA'TE ICING.}

Make a vanilla icing and add one tablespoonful of cold water to it. Scrape fine one ounce of No. 1 chocolate and put it in a small iron or granite-ware saucepan with two tablespoonfuls of confectioner's sugar and one tablespoonful of hot water. Stir over a hot fire until smooth and glossy, then add another tablespoonful of hot water. Stir the dissolved chocolate into the vanilla icing.

\section{CHOCOLATE ICE-CREAM.}

For about two quarts and a half of cream use a pint and a half of milk, a quart of thin cream, two cupfuls of sugar, two ounces of No. I chocolate, two eggs, and two heaping tablespoonfuls of flour.

Put the milk on to boil in the double-boiler. Put the flour and one cupful of the sugar in a bowl; add the eggs, and beat the mixture until light. Stir this into the boiling milk and cook for twenty minutes, stirring often.

Scrape the chocolate and put it in a small saucepan. Add four tablespoonfuls of sugar (which should be taken from the second cupful) and two tablespoonfuls of hot water. Stir over a hot fire until smooth and glossy. Add this to the cooking mixture.

When the preparation has cooked for twenty minutes take it from the fire and add the remainder of the sugar and the cream, which should be gradually beaten into the hot mixture. Set away to cool, and when cold, freeze.

\section{CHOCOLATE PUDDING.}

For a small pudding use one pint of milk, two tablespoonfuls and a half of corn-starch, one ounce of chocolate, two eggs, five tablespoonfuls 
of powdered sugar, one-fourth of a teaspoonful of salt, and half a teaspoonful of vanilla extract.

Mix the corn-starch with one gill of the milk. Put the remainder of the milk on to boil in the double-boiler. Scrape the chocolate. When the milk boils, add the corn-starch, salt, and chocolate, and cook for ten minutes. Beat the yolks of the eggs with three tablespoonfuls of the sugar. Pour the hot mixture on this and beat well. 'Turn into a pudding-dish that will hold about a quart, and bake for twenty minutes in a moderate oven.

Beat the whites of the eggs to a stiff, dry froth, and gradually beat in the remaining two tablespoonfuls of sugar and the vanilla. Spread this on the pudding and return to the oven. Cook for fifteen minutes longer, but with the oven-door open. Serve either cold or hot.

\section{BAVARIAN CHOCOLATE CREAM.}

For one large mould of cream, use half a package of gelatine, one gill of milk, two quarts of whipped cream, one gill of sugar, and one ounce of chocolate.

Soak the gelatine in the cold water for two hours. Whip and drain the cream, scrape the chocolate, and put the milk on to boil. Put the chocolate, two tablespoonfuls of sugar, and one of hot water, in a small saucepan, and stir on a hot fire until smooth and glossy. Stir this into the hot milk. Now add the soaked gelatine and the remainder of the sugar. Strain this mixture into a basin that will hold two quarts or more. Place the basin in a pan of ice-water and stir until the mixture is cold, when it will begin to thicken. Instantly begin to stir in the whipped cream, adding half the amount at first. When all the cream has been added, dip the mould in cold water and then turn the cream into it. Place in the icechest for an hour or more.

At serving-time dip the mould in tepid water. See that the cream will come from the sides of the mould, and turn out on a flat dish. Serve with whipped cream. 

0,7802699

HD 9195

B 72

$W 349$
1891 

